\section{P.1.03 MORTALITY ANALYSIS IN DIFFERENT EXPOSURE GROUPS OF COAL MINERS IN ROSTOV REGION OF THE RUSSIAN FEDERATION}

${ }^{1}$ Igor Bukhtiyarov*, ${ }^{2}$ Tatyana Pictushanskaya, 'Galina Tikhonova, 'Tatyana Gorchakova, ${ }^{1}$ Maria Bryleva, ${ }^{1}$ Anastasya Churanova, ${ }^{1,3}$ Evgeny Kovalevskiy. ${ }^{1}$ FSBSI Izmerov Research Institute Of Occupational Health, Moscow, Russian Federation; ${ }^{2}$ Treatment and Rehabilitation Centre ? 2, Center of Occupational Health, Shakhty, Rostov region, Russian Federation; ${ }^{3}$ I.M. Sechenov First Moscow State Medical University (Sechenov University), Moscow, Russian Federation

\subsection{6/OEM-2019-EPI.209}

Introduction The Rostov region was one of the largest centers of coal mining in Russia during XIX-XX centuries. The longterm effects of work in coal mines were investigated with the use of database of the Rostov regional center of occupational health.

Aim Assessment of mortality risks in different exposure groups of coal miners.

Methods A cohort of 9980 coal miners with established occupational diseases was formed by the Rostov regional center of occupational health. The follow-up period was 26 years (01.01.1990-31.12.2015). By the end of the follow-up period 1898 miners were alive and 8082 died. In result there were 138768 person-years of follow-up. The male population of Rostov region was used as reference group.

Two different exposure groups were created. First one included main professions - clearing face miners and shaft miners (5941 persons, 79978 person-years). Maximum dust concentrations reached $270-300 \mathrm{mg} / \mathrm{m} 3$, vibration levels $130 \mathrm{~dB}$, noise levels - $130 \mathrm{dBA}$. The second one included miners of auxiliary professions (shot-firers, wiremen, loco drivers, etc.) - 4039 persons, 58790 person-years. The maximum exposure levels were lower, 100-130 mg/m3, $110 \mathrm{~dB}, 105$ dBA, respectively.

Results The standardized mortality ratio in the cohort (SMR) was 1.47 (CI 1.42-1.51). In the group with length of service up to 10 years, $\mathrm{SMR}=1.01 \quad(0.91-1.13), \quad 10-19$ years $\mathrm{SMR}=1.33 \quad(1.27-1.39), \quad 20$ years and more $\mathrm{SMR}=1.91$ (1.80-2.02).

In both groups the SMR was higher than in reference population. $\mathrm{SMR}=1.57(1.50-1.63)$ and $\mathrm{SMR}=1.32(1.25-1.39)$ respectively. The difference between subgroups was also statistically significant $\mathrm{SMR}=1.19(1.14-1.24)$

Conclusion Results of follow up demonstrated elevated risks of mortality for former coal miners. A 'dose (time) - effect' relationship for mortality levels were also established.

\section{P.1.04 CORRELATION BETWEEN SCALP HAIR LEAD LEVELS AND BLOOD LEAD LEVELS OF LEAD BATTERY MANUFACTURING WORKERS}

Kate Chaivatcharaporn*. Samutprakan Hospital, Samutprakan, Thailand

\subsection{6/OEM-2019-EPI.210}

A group of 107 lead battery manufacturing workers, whose blood lead levels were above $30 \mathrm{mcg} / \mathrm{dl}$, have been monthly tested for blood lead levels due to the company health policy since 2016. In 2018, 83 workers were enrolled in the scalp hair lead analysis project using cloud point extraction (CPT), ultrasonic acid digestion (UAD) and flame atomic absorption spectrometry (FAAS). This study aimed at finding correlation between hair lead levels and serial blood lead levels. Data were obtained with permission from each workers and were analyzed using paired t-test.

All subjects were male workers at the age of $25-58$. The working period in this factory ranged from 1-34 years. Latest blood lead levels range from 31.22-58.7 mcg/dl. Hair lead levels ranged from 10.79-712.09 $\mathrm{mcg} / \mathrm{g}$ in proximal hair segment $(\mathrm{n}=83)$ and $41.47-688.64 \mathrm{mcg} / \mathrm{g}$ in distal hair segment $(n=15)$. Mean hair lead levels were 163.98 and $259.18 \mathrm{mcg} / \mathrm{g}$ in proximal and distal hair segment.

The correlation between hair lead levels and 5 consecutive months blood lead levels before the time of hair sample collection were found to be statistically significant ( $p$ 0.008, $p$ 0.030, p 0.021, p 0.009, p 0.019). Lead levels of distal hair segment were $9.72 \mathrm{mcg} / \mathrm{g}$ higher than proximal hair segment (p 0.002). Furthermore, significant correlation between distal hair segment lead levels and blood lead levels at some months during 3 year-period were found, but not for the prior 5 consecutive months.

\section{P.1.05 DEVELOPING A WORKPLACE INTELLIGENCE SYSTEM FOR EXPOSURE-CONTROL IN GREAT BRITAIN (WISE-GB)}

Yiqun Chen* , Andrew Curran. Health and Safety Executive, Buxton, UK

\subsection{6/OEM-2019-EPI.211}

The Health and Safety Executive (HSE) is a risk based regulator for workplace health and safety in GB. It has an intelligence-led operational approach. To inform HSE's risk control strategies, WISE-GB is developed to capture and integrate diverse but relevant data sources on an ongoing basis to generate intelligence, in a timely fashion, through enhanced analytic operation (i.e. statistical modelling, spatial and temporal analyses and expert interpretation) for monitoring and evaluation of the effectiveness of workplace exposure-control in GB.

A workshop was organised in October 2017 to bring stakeholders across HSE to develop a common vision for WISE-GB and to identify the next steps for development. WISE-GB will generate national representative intelligence on the patterns (levels and distributions) of risk exposure to important hazards, which should support: 1) risk assessment, prioritisation and targeting risk control efforts; and 2) monitoring and evaluation of interventions, where reliable intelligence on improvement of exposure-control is critical in linking positive changes in attitude and behavioural about workplace exposures to better prevention of work-related ill health.

A feasibility study will be presented, using Respirable Crystalline Silica (RCS) as an example, to illustrate WISE-GB development methods. This include: 1) capturing historical data as well as data gathered continuously through HSE operation and research, 2) accessing and utilisation inspection information, industry data, and data from other industrial countries to fill the potential data gaps; and 3) integrating diverse data sources to generate national representative intelligence. We will also demonstrate how the intelligence from WISE-GB contributes to the monitoring and evaluation of the HSE Health and Work programme on prevention of Occupational Lung Disease (OLD). These will help HSE towards developing a fit-for-purpose WISE-GB to generate real-time national picture of the effectiveness of exposure-control in GB workplaces.

(C) British Crown copyright (2019) 